\title{
Suitability of Rice Husk Ash (RHA) with lime as a soil stabilizer in geotechnical applications
}

\author{
B. H. J. Pushpakumara ${ }^{1 *}$ and W. S. W. Mendis ${ }^{2}$
}

\section{${ }^{*}$ Correspondence:}

pushpakumarabhj@kdu.ac.lk

1 Department of Civil

Engineering, Faculty

of Engineering, General Sir

John Kotelawala Defence

University, Colombo, Sri

Lanka

Full list of author information

is available at the end of the article

\begin{abstract}
Soils containing significant levels of silt or clay generally exhibit unacceptable engineering properties (i.e. low strength, high compressibility and high level of volumetric changes) when exposed to variation in moisture content. Chemical stabilizers such as cement and lime which are currently practiced, are often high-priced and unhygienic in terms of environmental sustainability. The prevailing study intended to explore the potential of the local Rice Husk Ash (RHA) which is an agricultural waste, with lime as a soil stabilizer. This experimental study was conducted on clayey soil with high plasticity. Different mixture proportions of RHA (i.e. 5\%, 10\%, 20\% and 30\%) and lime (i.e. 10\% and 20\%) were used to treat the parent soil. Observations were made for variations in index (i.e. liquid limit, plastic limit, sieve analysis, etc.) and mechanical properties (i.e. compressibility, permeability and shear strength) of treated soils soon and 28 days after mixing. It was found that $10 \%$ of RHA and $20 \%$ of lime by dry soil weight as the optimum dosage for the treatment. This optimum dosage increases the unconfined compressive strength and internal friction angle by $54.05 \%$ and $60.48 \%$, respectively and reduces plasticity index by $56.67 \%$ at 28 days after mixing. It could be identified that RHA and lime mixture was capable of improving index and mechanical properties of soil, positively.
\end{abstract}

Keywords: Soil Stabilization, Rice Husk Ash (RHA), Lime, Unconfined Compressive Strength, Pozzolanic reaction

\section{Introduction}

In most civil engineering construction projects, it is very usual that the local subsoil in sites is not suitable in the geotechnical viewpoint. Expansive and collapsible soils having high plasticity are very responsive to changes in moisture content and show excessive volume changes. The settlements caused by swelling or shrinkage are notably greater than elastic deformation resulting large scale damages to the overlying structures such as ground cracks, building cracks, heaving and rutting of pavement, falling of canal lining, eave of beds of canal and etc. Therefore, prior to construction, soil improvement needed to be done to enhance its mechanical behaviour to suit with the construction requirements. This can be performed by soil stabilization which is the method of treating soils to improve mechanical properties so that they become more suitable for construction beyond their original classification. author(s) and the source, provide a link to the Creative Commons licence, and indicate if changes were made. The images or other third party material in this article are included in the article's Creative Commons licence, unless indicated otherwise in a credit line to the material. If material is not included in the article's Creative Commons licence and your intended use is not permitted by statutory regulation or exceeds the permitted use, you will need to obtain permission directly from the copyright holder. To view a copy of this licence, visit http:// creativecommons.org/licenses/by/4.0/. 
Soil stabilization is being used for numerous engineering works, as its applicability to treat a variety of sub-grade materials. The most frequent applications are the pavement construction, railways and airfield runaways where it is used in improving bearing capacity, stiffness and structural rigidity of pavement layers to avoid unacceptable plastic deformation and thereby reduce pavement thickness [17]. The main intention of these applications is to enhance the strength of soil and minimize the cost of construction by making optimum use of locally available materials. All the soil stabilizing methods can be categorized into mechanical stabilization and chemical stabilization. One or both of these methods are performed in almost all road and other civil engineering construction process. The mechanical method refers to the stabilization by altering the physical nature of raw soil particles using methods such as compaction, dewatering, soil reinforcement (soil nailing) and addition of graded aggregates. The main objective is to reduce volume changes, increase stability and drainability of soil. Under chemical methods, soil is stabilized through the chemical reactions between additive (cementitious compound) and soil minerals. At present, common binders used in soil stabilization are lime and cement. These materials are not environmentally sustainable due to their total reliant on natural resources. Production of Portland cement is associated with greenhouse gas emission which cater global warming and related climatic changes. In addition to that, these materials have rapidly increased in price due to the demand and sharp increment in the cost of energy. Dependency on the use of industrially manufactured additives have kept material cost (especially road construction) financially high. As a result, underdeveloped and poor nations of the world have been discouraged to provide accessible roads to their rural dwellers where higher percentage of their population are mostly, agriculturally dependent. Stabilization methods can be adopted on large scale when the treatment is low cost and durable. In addition, as the use of such waste materials is a recycling sustainable measure that benefits the environment, utilization of industrial by-products [11] as soil stabilizing additive has become more important.

Rice husk which is a by-product obtained in bulk amount from rice milling of paddy, is an agricultural waste. During milling of rice, nearly $72 \%$ of paddy weight is received as rice while $5-8 \%$ of broken rice and bran and about $20-22 \%$ of paddy weight is received as husk [7] and [9]. In fact, about 100 million tons of rice husk is generated annually in the world [3]. Most of the rice husk obtained during milling process is either dumped as a waste or burnt. However, rice husk is used as fuel in rice mills to generate steam to blanch rice at low combustion efficiency. In addition to that, rice husk is burnt as fuel at high combustion efficiency in brick kilns. Rice husk contains about $75 \%$ organic volatile matter and the balance $25 \%$ becomes ash which is known as Rice Husk Ash (RHA) during the burning process $[2,15]$ and $[16]$, that is commonly dumped as waste materials. RHA has been categorized under pozzolana, as it comprised of nearly $85-92 \%$ silica and about $3.0 \%$ and $1.0 \%$ aluminium oxide and iron oxides respectively, which are compounds that attribute to pozzolanic reaction $[4,8]$ and $[10]$. The silica is in the form of amorphous (non-crystalline silica) and the ash contains higher surface area that are associated with high pozzolanic reactivity [1] and [14]. Since RHA is a supplementary cementitious material, it is apparent that it is capable of improving the mechanical properties of soils for sub-grade, backfilling purposes. The number of researches on the use of agricultural wastes like RHA as an additive along with any conventional material for 
the stabilization of the fine grain soil is rare. So, utilization of such material for improving the properties of fine grain soil needs to be investigated.

The burning temperature of the risk husk should be maintained in between 500 to 700 ${ }^{\circ} \mathrm{C}$ in order to produce RHA with high pozzalonic activity [6]. RHA is used as fuel for brick burning process and the temperature varies from 550 to $750{ }^{\circ} \mathrm{C}$ within the brick kiln [10]. With the presence of $\mathrm{Ca}(\mathrm{OH})_{2}$, the $\mathrm{SiO}_{2}$ and $\mathrm{Al}_{2} \mathrm{O}_{3}$ react with dissolved $\mathrm{Ca}^{2+}$ and $\mathrm{OH}^{-}$and produce secondary cementitious product called "Tobermorite gel" [10] (Calcium Silicate Hydrate (C-S-H) and Calcium Aluminates Hydrate (C-A-H)). It was observed that the $\mathrm{Ca}^{2+}$ in the lime react with $\mathrm{SiO}_{2}$ in the $\mathrm{RHA}$ with the presence of moisture and improve the strength of the paste [13] and [19]. Therefore, this research intended on investigating the optimum dosage of RHA and lime mixture for soil stabilization through the laboratory observation of effects of binder on some geotechnical properties of clayey soil which are relevant to evaluate the performance of sub-grade and backfill soils.

\section{Methodology}

\section{Materials}

Based on the visual inspection, a clayey soil was selected as the source of the soil material for the experimental study. The soil was amber in colour as shown in Fig. 1a. The collected soil was pulverized with wooden mallet to break lumps and then air-dried for at least $24 \mathrm{~h}$ since well air dried soil samples were required for laboratory testing according to AASHTO Standards.

Rice Husk Ash used for the present investigation was obtained from a brick kiln (Fig. 1b). In this kiln, rice husk was burnt at an increased temperature (i.e. $620^{\circ} \mathrm{C}$ ) and was the only material that was used as the fuel for the brick burning. The RHA collected from the kiln was free from debris and consisted particles of different sizes. Collected RHA was then sieved through $3 \mathrm{~mm}$ sieve and passing fraction was collected for testing purposes. The chemical analysis of the RHA was conducted by using X-ray fluorescence analyser. Commercial grade quick lime was used for the sample preparation (Fig. 1c) since it is more reactive in pozzolanic reaction [12] compared to hydrated lime.

\section{Sample preparation}

Sample preparation for testing was done as per the requirement of the tests. The required amount of materials was weighed out on the weight basis as per the percentage

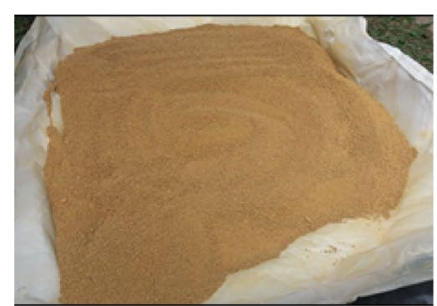

(a)

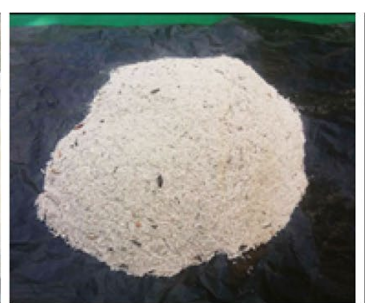

(b)

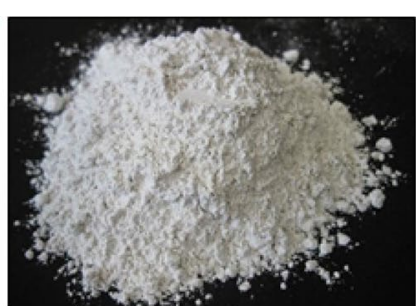

(c)

Fig. 1 Materials for test a Clay soil b Rice Husk Ash c Lime 
to be added to the dry soil for testing. The soil and the stabilizing agents were then mixed together in dry conditions thoroughly before testing as per the design mix proportions. For determining the quantitative information about the treated soil, RHA was mixed with soil in increasing proportion of $5 \%, 10 \%, 20 \%$ and $30 \%$ by weight of dry soil. Further for evaluating the effect of lime, increasing proportions of lime with respect to the Table 1, in dry condition by weight of dry soil was added with the soil mixed with RHA varying from 5 to $30 \%$. In addition to that clay soil without RHA and lime (i.e. $0 \%$ ) was tested as Control Sample (CS). Three samples were prepared for each category and average test results were obtained.

\section{Experimental study}

Index and engineering properties tests were carried out on virgin soils. In the second phase of the study, the same laboratory tests were performed on aforementioned treated soil samples (Table 1) to observe the changes in the properties of soil at soon after and at 28 days after of mixing. Test results were then analysed along with the results of the control samples to evaluate the combined effects of lime and RHA on the geotechnical properties of the original soil and thereby to determine the optimal proportion for stabilization. Laboratory experiments, conducted were;

- Liquid Limit Test (AASHTO: T089-96)

- Plastic Limit Test (AASHTO: T090-96)

- Proctor Compaction Test (AASHTO: T180-01)

- Direct Shear Test (ASTM: D 3080-98)

- Unconfined Compressive Strength Test (ASTM: D2166-16)

- Wet Sieve Analysis (ASTM: D 1140-00)

- Specific Gravity Test (ASTM: D 854-02)

All of the above tests were conducted on virgin soil to identify its natural behaviour. Only Atterberg limits, compaction, direct shear and unconfined compressive strength tests were performed on the treated soil (i.e. RHA mixed soil).

Table 1 Mix proportions of soil, RHA and quick lime

\begin{tabular}{lllcl}
\hline Series & Sample No & Soil (\%) & RHA (\%) & Lime (\%) \\
\hline 1 & 1 & 100 & 5 & 0 \\
& 2 & 100 & 10 & 0 \\
& 3 & 100 & 20 & 0 \\
& 4 & 100 & 30 & 0 \\
& 1 & 100 & 5 & 10 \\
& 100 & 10 & 10 \\
& 2 & 100 & 20 & 10 \\
& 3 & 100 & 30 & 20 \\
& 4 & 100 & 5 & 20 \\
& 1 & 100 & 10 & 20 \\
& 2 & 100 & 30 & 20 \\
\hline
\end{tabular}


Table 2 Properties of raw soil

\begin{tabular}{lc}
\hline Particle size distribution & \\
\hline Gravel (\%) & 0 \\
Sand (\%) & $<10 \%$ \\
Clay + Silt (\%) & $>90 \%$ \\
Liquid limit (\%) & 66.5 \\
Plastic limit (\%) & 33.5 \\
Plasticity index (\%) & 33 \\
Maximum dry density $\left(\mathrm{kg} / \mathrm{m}^{3}\right)$ & 1489.4 \\
Optimum moisture content $(\%)$ & 26.8 \\
Internal friction angle $\left(^{\circ}\right)$ & 21 \\
Cohesion $(\mathrm{kPa})$ & 11.6 \\
Unconfined compressive strength $(\mathrm{kPa})$ & 79 \\
\hline
\end{tabular}

Table 3 Chemical composition of RHA (Wt. \%)

\begin{tabular}{llllllll}
\hline $\mathrm{SiO}_{\mathbf{2}}$ & $\mathrm{Al}_{2} \mathrm{O}_{\mathbf{3}}$ & $\mathrm{Fe}_{2} \mathrm{O}_{\mathbf{3}}$ & $\mathrm{CaO}$ & $\mathbf{M g O}$ & $\mathrm{Na}_{\mathbf{2}} \mathrm{O}$ & $\mathrm{K}_{\mathbf{2}} \mathrm{O}$ & Loss in ignition \\
\hline 90.04 & 1.83 & 1.37 & 1.28 & 0.73 & 0.42 & 2.61 & 1.72 \\
\hline
\end{tabular}

\section{Results and discussion}

Table 2 indicates the test results for the laboratory experiments conducted on raw unsuitable soil. According to the AASHTO soil classification, the selected soil belongs to the group A-7-5, that is highly clay. Group index for the soil was 40 . Based on the group index, selected soil can be identified as very poor for a subgrade material.

Table 3 shows the chemical composition of RHA which was evaluated by using $\mathrm{X}$-ray fluorescence analyser. RHA was collected from a brick kiln where RHA used as fuel for brick burning process. The measured average burning temperature of the RHA was $620^{\circ} \mathrm{C}$. The temperature was within the ideal value (i.e. $500{ }^{\circ} \mathrm{C}$ to $700{ }^{\circ} \mathrm{C}$ ) [10] for producing an ash with high pozzolanic activity. According to the Table 3, RHA sample contains total amount of $93 \%$ of silica, aluminium oxide and iron oxides which are compounds that attribute to pozzolanic reaction.

\section{Effects on plasticity index}

Based on the Atterberg limit test results, variation of plasticity index which is one of significant index property that measures plasticity of soil could be evaluated for the treated soil. Figure 2 illustrates the variation of plasticity index with the addition of binder mixture at soon after mixing and 28 days after mixing. With increase in RHA content from 0 to $30 \%$, plasticity index decreased up to first $5 \%$ increment then increased with slight fluctuations for all three lime contents for soon after mixing of binder mixture. After 28 days, plasticity index decreased up to first $10 \%$ increment then increased as similar to soon after mixing. Results also showed that, up to $0-10 \%$ of lime content, plasticity index has reduced and when lime content was increased beyond $10 \%$ of lime, plasticity index increased. Minimum plasticity index could be observed for 5\% RHA and 10\% lime (i.e. soon after mixing) was 16.6, 


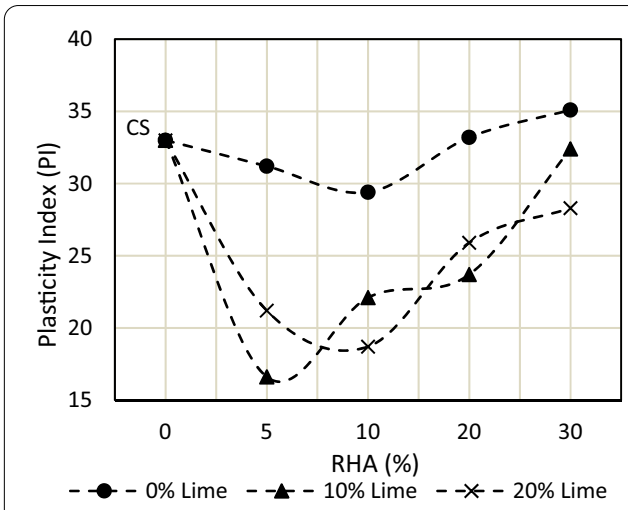

(a)

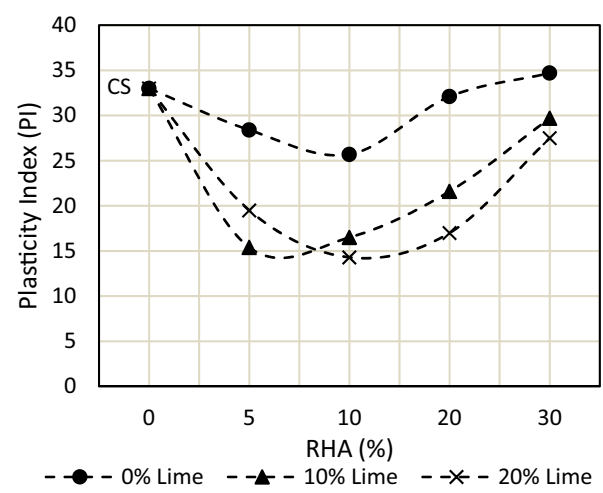

(b)

Fig. 2 Variation of plasticity index with RHA and lime content $\mathbf{a}$ Soon after mixing $\mathbf{b} 28$ days after mixing

showing a reduction of $49.7 \%$ and for $10 \%$ RHA and $20 \%$ lime (i.e. 28 days after mixing) was 14.3 , showing a reduction of $56.67 \%$, respectively.

Initial reduction of the PI could be attributed to the initial reduction in LL and increment in PL due to the factors which are less water affinity caused by replacement of clay minerals with binder and increased flocculation caused by cation exchange in the soil additive mixture. Reduction of PI in soil (i.e., by $36 \%$ ) observed in the test done by Zha et al. [20] when fly ash (i.e. 12\%) used as the binder for a similar type of soil (i.e. high plastic clay) is comparatively less than the reduction of PI in soil obtained in this study. Durga et al. [5] have stated that a reduction of $96 \%$ could be observed in PI when a mixture of 38\% quarry dust and $2 \%$ lime was as the binder. Even though the plasticity reduction is greater, it is not that realistic in terms of the required amount (i.e. $38 \%$ of quarry dust) and availability of material.

\section{Effects on compaction characteristics}

\section{Maximum Dry Density (MDD)}

With increase in RHA content from 0 to $30 \%$, MDD of the treated soil decreased soon after mixing. In addition to that, with increase in lime content from 0 to $20 \%$, MDD increased as shown in Fig. 3. Reduction of MDD with addition of RHA at constant lime content could be considered to be a result of addition RHA, which has relatively low specific gravity of 1.95 compared to that of the raw soil which has a specific gravity of 2.59. This might be resulted due to some other factors like formation of Tobermorite gel from pozzolanic reactions that covers soil particles resulting in larger particles with larger voids, thus lesser density.

For the lime amount of $10 \%$ and $20 \%$, the MDD of treated soils at 28 days after mixing is increased for RHA content from 0 to $10 \%$. It is the $4.6 \%$ development of the MDD compared to Control Sample (CS). After that, MDD is decreased with the increment of RHA content. Increase of MDD of mixture might be due to the solidification of soil particles with the time. Addition of lime would be increased the utilization of amount of RHA. 


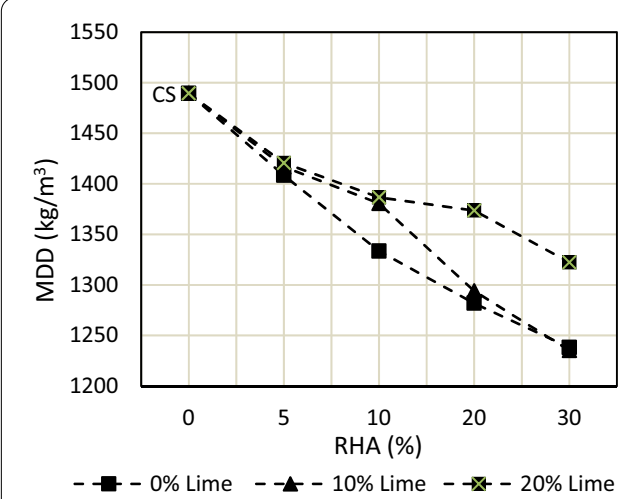

(a)

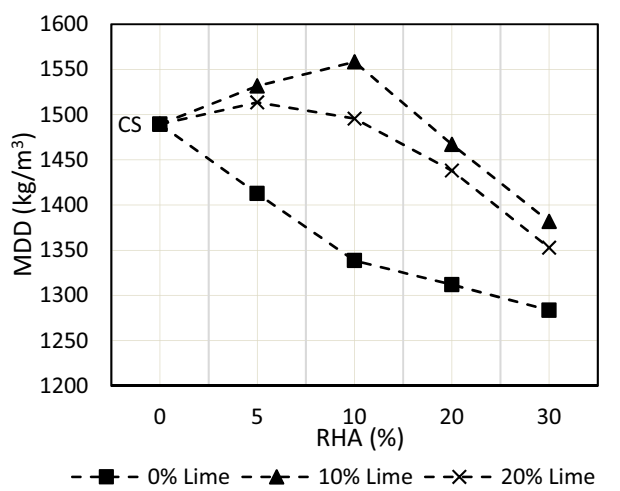

(b)

Fig. 3 Effect of RHA and lime mixture on Maximum Dry Density (MDD) a Soon after mixing $\mathbf{b} 28$ days after mixing

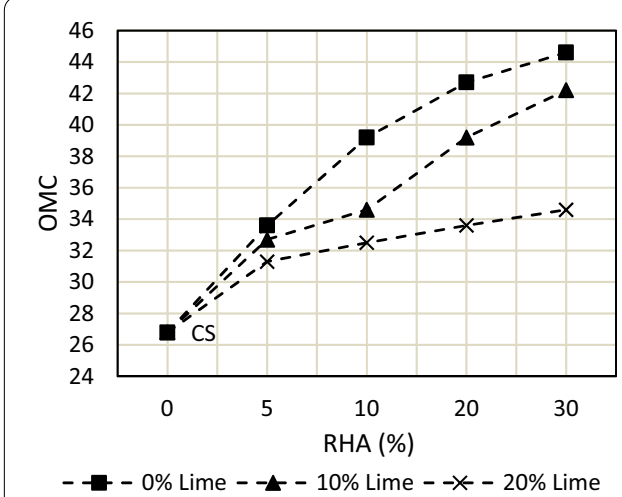

(a)

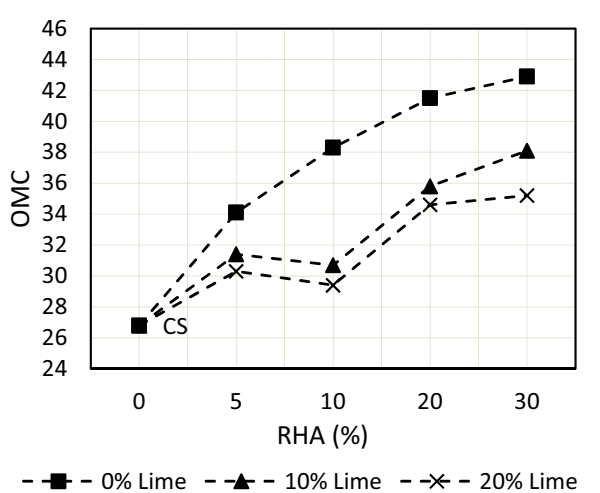

(b)

Fig. 4 Effect of RHA and lime mixture on Optimum Moisture Content (OMC) a Soon after mixing $\mathbf{b} 28$ days after mixing

\section{Optimum Moisture Content (OMC)}

It can be observed that, OMC of treated soil increased with the addition of RHA from 0 to $30 \%$ while, increase in lime content from 0 to $20 \%$, resulted in decreased OMC as shown in Fig. 4. Increase in OMC with the addition of RHA could be possibly due to the addition of RHA, caused increased amount of silica and alumina, which made the mixture to require more water for the pozzolanic reaction. Further, water absorption of RHA is higher than raw material (i.e. soil). Therefore, more water was needed to compact the treated soil to obtain maximum density. The reduction in OMC with the addition of lime for each RHA content, could be attributed to the cation exchange between stabilizer and expansive clay soil, reduced the thickness of diffuse double layer and promoted the flocculation. This flocculation of the soil solid particles implies that the water-binder-soil mixtures could be compacted with lower moisture content, hence reduced OMC. Favourable changes in the compaction parameters for treated soil are to obtain a higher value of MDD and a lower value of OMC. In fact, past researches which 
are, Zha et al. [20] and Yadu \& Tripathi [18] indicated that $-1.8 \%$ and $-9.1 \%$ change in MDD and $-6.3 \%$ and $+36 \%$ change in OMC could be observed in their subjective clay soil for binder fly ash (12\%) and fly ash (3\%) + blast furnace slag $(6 \%)$, respectively. When considering these two studies, though the use of fly ash (12\%) is more preferred, toxic constituents, free availability and cost are some related problems. In this study, even though the results showed more preferable conditions for lime content of $20 \%$, it is better to go for a lime content of $10 \%$ which is also acceptable based on the facts that cost and embodied energy.

\section{Effects on shear strength properties Internal friction angle}

In Fig. 5, it can be clearly seen that, internal friction angle of soil increased with the addition of RHA and lime. Soon after mixing, the Increases were $23.81 \%, 33.33 \%$ and $42.86 \%$ for $0 \%, 10 \%$ and $20 \%$ of lime contents, respectively. After 28 days of mixing, the increases were $33.33 \%, 43.33 \%$ and $60.48 \%$ for $0 \%, 10 \%$ and $20 \%$ of lime contents, respectively. This increase can be considered to be as a result of (a) when increasing the lime content, more cations on the surface of clay particles could be replaced by $\mathrm{Ca}^{2+}$ ions reducing the water affinity and diffuse double layer thickness resulted in increased friction angle, (b) with the addition of RHA, pozzolanic reaction was promoted which would increase the bonding stress due to the formation of cementitious compounds such as CSH and CAH. When considering rate of increment, rates for the increase in RHA from 0 to $5 \%$ were greater than the rates for the increase in RHA from 5 to $30 \%$. This was because, higher $\mathrm{Ca}^{2+}$ ion concentration caused replacement of more cations on the surface of the clay particles.

\section{Cohesion}

As shown in the Fig. 6, cohesion of the mixture was increased slightly up to first $0-5 \%$ increase in RHA content for all three lime contents soon after mixing. Further increase in RHA at constant lime amount resulted in decreased cohesion of soil.

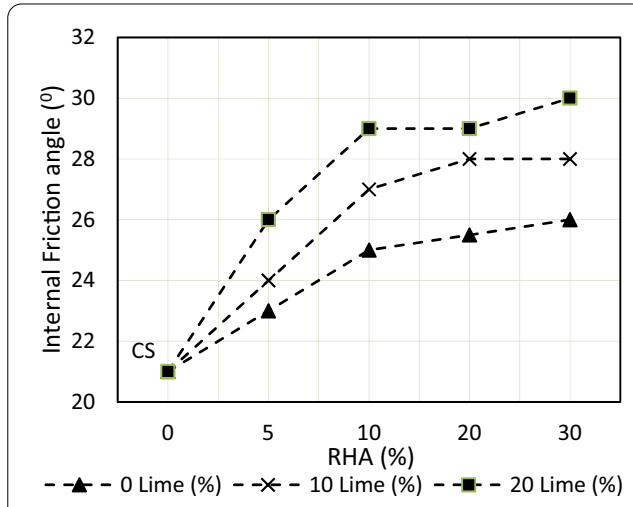

(a)

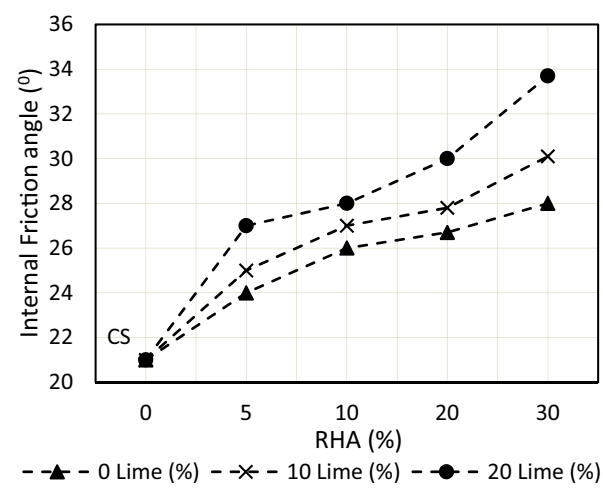

(b)

Fig. 5 Effect of RHA and lime mixture on friction angle $\mathbf{a}$ Soon after mixing $\mathbf{b} 28$ days after mixing 


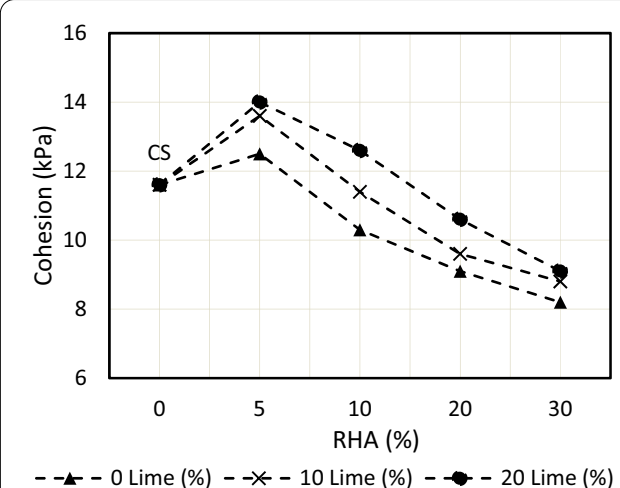

(a)

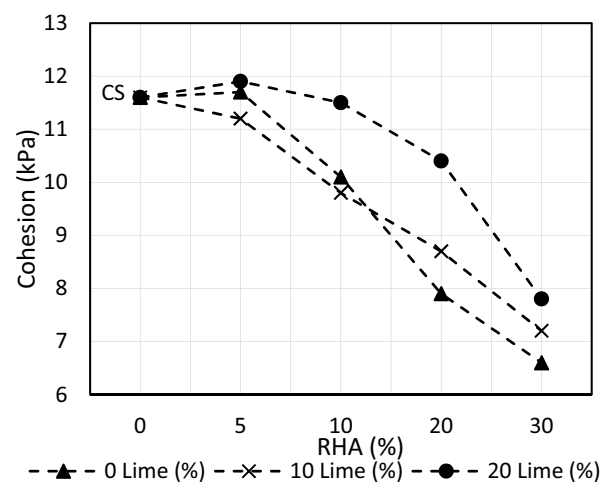

(b)

Fig. 6 Effect of RHA and lime mixture on cohesion a Soon after mixing $\mathbf{b} 28$ days after mixing

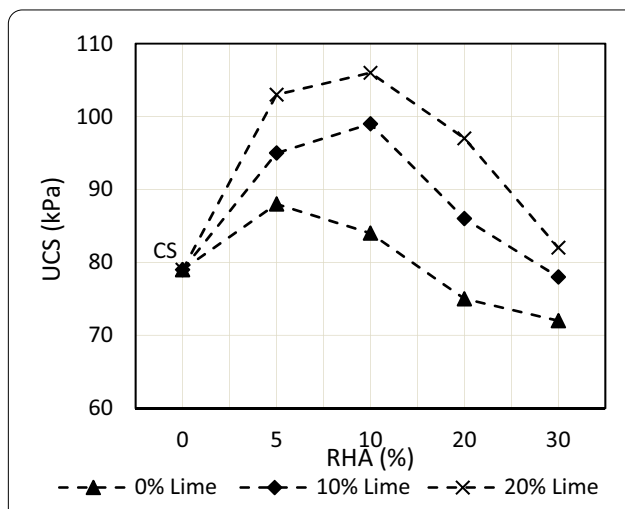

(a)

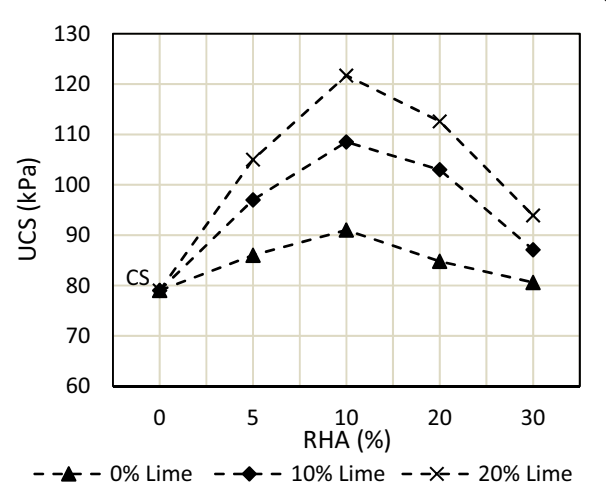

(b)

Fig. 7 Effect of RHA and lime mixture on UCS of treated soil $\mathbf{a}$ Soon after mixing $\mathbf{b} 28$ days after mixing

When increasing the lime content considering constant RHA content, increase in cohesion could be observed. This was due to the cation exchange resulted in flocculation of particles increasing the surface area of particle which promoted higher electrostatic attraction between particles.

\section{Effects on Unconfined Compressive Strength (UCS)}

Results showed that (Fig. 7), the Unconfined Compressive Strength (UCS) increased when adding RHA up to $10 \%$, adding additional RHA gave a reduction in unconfined compressive strength at all three lime contents. The initial increment might be due to quantity of RHA could induce pozzolanic reaction and cementitious compounds that strength increase, while the additional amount of RHA could act as unbounded particles, forming weak bonds between the soil and the cementitious compounds formed. Increase in UCS with addition of lime for any RHA content resulted because of the promoted formation of cementitious compounds between the $\mathrm{Ca}(\mathrm{OH})_{2}$ formed in the soil and the pozzolans available in the RHA. For soon after mixing of binder, maximum 
UCS could be observed when nearly 10\% RHA and 20\% lime were added, which was $106 \mathrm{kPa}$, showing a $34.18 \%$ increase. After 28 days of mixing, the maximum UCS was $121.7 \mathrm{kPa}$, showing a $54.05 \%$ increase for same mix proportions (i.e. $10 \%$ RHA and $20 \%$ lime). Increase in UCS could be expected with time due to continuation of the pozzolanic action (i.e. gaining strength). The optimum dosage in the viewpoint of UCS results for improving strength of the treated soils was therefore $10 \%$ of RHA and $20 \%$ of lime. When comparing results of this study with past research work, similar changes in UCS could be seen for both binders $12 \%$ fly ash [20] and 10\% RHA + 10\% lime which was $25 \%$ of increase in UCS. According to the results, increasing the lime content is more preferred in the viewpoint of UCS variation.

During hydration process, $\mathrm{SiO}_{2}$ and $\mathrm{Al}_{2} \mathrm{O}_{3}$ in the mixture dissolve due to increase of $\mathrm{p}^{\mathrm{H}}$ value. The hydrous Silica and Alumina react with the $\mathrm{Ca}^{2+}$ (from quick lime) and produce insoluble compounds ( $\mathrm{CSH}, \mathrm{CAH}$ ) often called as secondary cementitious products or Tobermorite gel. With the continuation of curing, insoluble compounds produce hardens the treated soil particles. This might be contributed to increase the unconfined compressive strength of treated soil at 10\% RHA content. The addition of RHA caused to decrease in unconfined compressive strength, because there might be a lack of $\mathrm{Ca}^{2+}$ for the continuation of pozzolanic reaction. The lime hardening process is a much slower reaction, which requires considerably longer time than the hydration of cement. This process (i.e. lime hardening) occurs well in hydrous environment. Therefore, the continuation of curing process continues the gain of compressive strength. In addition, the high temperature accelerates the chemical reactions and solubility of the silicates thus increases the rate of strength gain. Therefore, it is recommended to use hot water for curing of the treated soil. Moreover, higher $\mathrm{pH}$ may accelerate formation of secondary cementitious products. The RHA can be effectively used as a soil stabilizer, resulting to prevent the environmental pollution caused by open dumping of RHA. In addition, utilisation of RHA as soil stabilizer, would be reduced the $\mathrm{CO}_{2}$ emission from other soil stabilizers like cement (i.e. $\mathrm{CO}_{2}$ emission due to production of cement).

\section{Conclusions}

Experimental study of this research indicated noticeable positive improvements in index and engineering properties of the raw unsuitable soil which were plasticity, shear strength and compressive strength, at the same time, showing slight reduction in compaction properties. Furthermore, increases in engineering properties such as shear strength and compressive strength could be observed with time because of the pozzolanic action of the additive. Therefore, as a whole, it could be clearly identified that RHA and lime mixture has the potential of improving index and engineering properties of soil positively. When considering overall test results, the optimum dosage for the treatment is $10 \%$ of RHA and $20 \%$ of lime by weight of dry soil. Properties of stabilized soil are obviously dependent on the type of soil to be treated. Therefore, for soil with clay/ fine content $>90 \%$, LL around $60 \%$ and PI around 30, dosage of $10 \%$ of RHA and $20 \%$ of lime can be recommended to be used for soil stabilization. In geotechnical applications where lime is entirely used for stabilization on clay soil with high plasticity, usage 
of RHA could be promoted as a partial replacement of the primary additive. Since RHA is less expensive in terms of availability and material cost compared to cement and lime, usage of RHA as an alternative or as a partial replacement of lime in geotechnical applications, will reduce the cost for construction particularly in the rural areas of developing countries, solve related disposal problems while reducing the negative impacts on environment.

\section{Acknowledgements}

The authors would like to express their gratitude to the Department of Civil Engineering, Faculty of Engineering, General Sir John Kotelawala Defence University for providing technical support throughout this research.

Availability of data and materials

All data, models and code generated or used during the study appear in the submitted article.

\section{Declarations}

\section{Competing interests}

The authors declare that they have no known competing financial interests or personal relationships that could have appeared to influence the work reported in this paper.

\section{Author details}

${ }^{1}$ Department of Civil Engineering, Faculty of Engineering, General Sir John Kotelawala Defence University, Colombo, Sri Lanka. ${ }^{2}$ Faculty of Engineering, University of Ruhuna, Matara, Sri Lanka.

Received: 21 April 2021 Accepted: 22 September 2021

Published online: 02 February 2022

\section{References}

1. Adhikary S, Jana K (2016) Potentials of rice husk ash as a soil stabilizer. Int J Latest Res Eng Technol 2:40-48

2. Agus SM (2002) Utilization of uncontrolled burnt rice husk ash in soil improvement. Dimensi Teknik Sipil 4:100-105

3. Alhassan M (2008) Potentials of rice husk ash for soil stabilization. AU J Technol 11:246-250

4. Antiohos SK, Papadakis VG, Tsimas S (2014) Rice husk ash (RHA) effectiveness in cement and concrete as a function of reactive silica and fineness. Cement Concrete Res 61:20-27

5. Durga N, Deepiya R, Steffi J, Ayyappan S (2014) Stabilization of clay soil using quarry dust and lime. Int J Adv Inform Sci Technol 32:111-114

6. Jamil M, Khan MNN, Karim MR, Kaish ABMA, Zain MFM (2016) Physical and chemical contributions of Rice Husk Ash on the properties of mortar. Constr Build Mater 128:185-198

7. Kishore R, Bhikshma V, Prakash PJ (2011) Study on strength characteristics of high strength rice husk ash concrete. Procedia Eng 14:2666-2672

8. Oyetola E, Abdullahi M (2006) The use of rice husk ash in low-cost sandcrete block production. Leonardo Electron J Pract Technol 8:58-70

9. Pushpakumara BHJ, Kapukotuwa SBKDK, Samarasinghe BGCM, Subashi De Silva GHMJ (2011) Potential use of rice husk ash with lime in the manufacturing of masonry blocks. Annual Sessions of Society of Structural Engineers, Sri Lanka, pp 45-51

10. Pushpakumara BHJ, Subashi De Silva GHMJ (2012) Characteristics of Masonry Blocks Manufactured with Rice Husk Ash (RHA) and Lime. Engineer 45(03):1-10

11. Pushpakumara BHJ, Thusitha GA (2021) Development of a priority weights-based green building rating model. J Archit Eng 27(2):04021008. https://doi.org/10.1061/(ASCE)AE.1943-5568.0000465

12. Rogers C, Glendinning S (1993) Modification of clay soils using lime. Thomas Telford, London, pp 99-114

13. Safiuddin M, West JS, Soudki KA (2010) Hardened properties of self-consolidating high performance concrete including rice husk ash. Cement Concrete Composite 32(9):708-717

14. Sandhu RK, Siddique R (2017) Influence of rice husk ash (RHA) on the properties of self-compacting concrete: a review. Constr Build Mater 153:751-764

15. Subashi De Silva GHMJ, Perera BVA (2018) Effect of waste rice husk ash (RHA) on structural, thermal and acoustic properties of fired clay bricks. J Build Eng 18:252-259

16. Subashi De Silva GHMJ, Surangi MLC (2017) Effect of waste rice husk ash on structural, thermal and run-off properties of clay roof tiles. Constr Build Mater 154:251-257

17. Verma SK (2015) A laboratory study on use of bitumen emulsion in black soil. Int Res J Eng Technol 2:548-553

18. Yadu L, Tripathi RK (2013) Effects of granulated blast furnace slag in the engineering behaviour of stabilized soft soil. Procedia Eng 51:125-131. https://doi.org/10.1016/j.proeng.2013.01.019

19. Zareei SA, Ameri F, Dorostkar F, Ahmadi M (2017) Rice husk ash as a partial replacement of cement in high strength concrete containing micro silica: evaluating durability and mechanical properties. Case Stud Construct Mater 7:73-81

20. Zha F, DuY (2008) Behavior of expansive soils stabilized with fly ash. Nat Hazards 47:509-523 


\section{Publisher's Note}

Springer Nature remains neutral with regard to jurisdictional claims in published maps and institutional affiliations.

Submit your manuscript to a SpringerOpen ${ }^{0}$ journal and benefit from:

- Convenient online submission

- Rigorous peer review

- Open access: articles freely available online

- High visibility within the field

Retaining the copyright to your article

Submit your next manuscript at $\boldsymbol{\nabla}$ springeropen.com 